\title{
The Degradation of Mechanical Properties in Halloysite Nanoclay-Polyester Nanocomposites Exposed in Seawater Environment
}

\author{
Mohd Shahneel Saharudin, ${ }^{1,2}$ Jiacheng Wei, ${ }^{2}$ Islam Shyha, ${ }^{2}$ and Fawad Inam ${ }^{2}$ \\ ${ }^{1}$ Universiti Kuala Lumpur Institute of Product Design and Manufacturing (UniKL IPROM), Cheras, 56100 Kuala Lumpur, Malaysia \\ ${ }^{2}$ Department of Mechanical and Construction Engineering, Faculty of Engineering and Environment, Northumbria University, \\ Newcastle upon Tyne NE1 8ST, UK \\ Correspondence should be addressed to Mohd Shahneel Saharudin; mohd.saharudin@northumbria.ac.uk
}

Received 18 July 2016; Accepted 30 October 2016

Academic Editor: Michele Zappalorto

Copyright ( 2016 Mohd Shahneel Saharudin et al. This is an open access article distributed under the Creative Commons Attribution License, which permits unrestricted use, distribution, and reproduction in any medium, provided the original work is properly cited.

\begin{abstract}
Polyester based polymers are extensively used in aggressive marine environments; however, inadequate data is available on the effects of the seawater on the polyester based nanocomposites mechanical properties. This paper reports the effect of seawater absorption on the mechanical properties degradation of halloysite nanoclay-polyester nanocomposites. Results confirmed that the addition of halloysite nanoclay into polyester matrix was found to increase seawater uptake and reduce mechanical properties compared to monolithic polyester. The maximum decreases in microhardness, tensile and flexural properties, and impact toughness were observed in case of $1 \mathrm{wt} \%$ nanoclay. The microhardness decreased from $107 \mathrm{HV}$ to $41.7 \mathrm{HV}$ (61\% decrease). Young's modulus decreased from $0.6 \mathrm{GPa}$ to $0.4 \mathrm{GPa}$ (33\% decrease). The flexural modulus decreased from $0.6 \mathrm{GPa}$ to $0.34 \mathrm{GPa}$ ( $43 \%$ decrease). The impact toughness dropped from $0.71 \mathrm{~kJ} / \mathrm{m}^{2}$ to $0.48 \mathrm{~kJ} / \mathrm{m}^{2}$ (32\% decrease). Interestingly, the fracture toughness $K_{\mathrm{IC}}$ increased with the addition of halloysite nanoclay due to the plasticization effect of the resin matrix. SEM images revealed the significant reduction in mechanical properties in case of $1 \mathrm{wt} \%$ reinforcement which is attributed to the degradation of the nanoclay-matrix interface influenced by seawater absorption and agglomeration of halloysite nanoclay.
\end{abstract}

\section{Introduction}

Thermosetting polymers are used in various industrial applications [1]. In the marine environment, complex conditions such as high salinity, high pressure, high humidity, and alkaline corrosion accelerate the degradation of polymers and greatly reduce their reliability [2]. Bottles, vessels, and pipes are some of the common applications where seawater contact is unavoidable and can lead to the loss of inherent mechanical properties [3]. Unsaturated polyester (UP) resins are widely used in boat components, pipes, tanks, building panels, and automobiles due to their ease in processing, low viscosity, and relatively high chemical and corrosion resistance [4-6]. The formation of a three-dimensional cross-linking structure in UP from free-radical copolymerization between low molar mass that possesses several covalent $C=C$ bonds and the styrene produced localised plastic deformation in front of the crack tip, which leads to brittle failure [7]. So far, many studies have been carried out on thermoset polymers, epoxy, and phenolic and unsaturated polyester in order to improve their mechanical properties and reduce damage severity without losing their strength and stiffness. Numerous synthetic fibres (glass, carbon, Kevlar, etc.) have been increasingly used in producing good mechanical properties composite materials with low cost and light weight [7-13]. The rises of the utilisation of nanoreinforcements (e.g., carbon nanotubes, nano$\mathrm{SiO}_{2}$, nano- $\mathrm{Al}_{2} \mathrm{O}_{3}$ nanocrystalline metals, and nano- $\mathrm{TiO}_{2}$ ) and nanoclays have navigated the orientation of the literature on polymer nanocomposites to be one of the most popular areas for materials' improvement [14-16].

Halloysite is a clay mineral with the empirical formula $\mathrm{Al}_{2} \mathrm{Si}_{2} \mathrm{O}_{5}(\mathrm{OH})_{4}$ [17]. Halloysite nanoclay is an unusual and rare natural nanotubular material $[15,16,18]$. Up to now, the superior potential applications have been disappointed by the 
degradation of the polymer or failure to outperform other incumbent alternatives. Halloysite nanoclay can improve brittle polymers such as polyester at a very low cost [19]. The one-dimensional tubular porous structure on the mesoporous $(2-50 \mathrm{~nm})$ and macroporous $(>50 \mathrm{~nm})$ scale made halloysite nanoclay superior to many synthetic materials such as CNTs (carbon nanotubes) [20,21]. The unique properties lead to various applications of the halloysite nanoclay for controlled drug and other active molecules' release [22]. They also have been used as nanoreactors and adsorbents [23]. The mechanical properties of systems with halloysite nanoclay are not the only improvements that can be observed [2426]. The incorporation of halloysite nanoclay enhanced the nanocomposites' thermal stability and flame and corrosion resistance of composites as well [27].

Nanoclay as a filler in clay-polymer nanocomposites (CPN) was introduced by Du et al. in 2006 [27]. They have investigated the effect of nanoclay content on the mechanical properties of nanocomposites. In their study, the flexural modulus of the nanocomposites increased from $2711 \mathrm{MPa}$ (neat polypropylene) to $4557 \mathrm{MPa}$ (68\% increase). Deng et al. [28] reported the fracture toughness of the nanoclay particle modified epoxies. They have revealed the greatest improvement up to $50 \%$ in $K_{\mathrm{IC}}$ and $127 \%$ in $G_{\mathrm{IC}}$. This remarkable improvement was attributed to the large aspect ratios of halloysite nanoclay [28]. Albdiry and Yousif studied the tensile strength and modulus of unsaturated polyester nanocomposites [29]. The nanocomposites demonstrated an increase in mechanical properties by $7 \%$ and $10 \%$ in tensile strength and $7 \%$ and $12 \%$ in tensile modulus, respectively. Tang et al. revealed that the incorporation of small amounts of nanoclay in epoxy matrixes considerably enhanced impact toughness by $78 \%$ [30]. In another study by Albdiry et al., $61 \%$ fracture toughness enhancement was observed. Quaresimin et al. reported the fracture and interlaminar properties of claymodified epoxies and their glass reinforced laminates [31]. They reported that $40 \%$ improvement in the fracture toughness was observed particularly with Cloisite 30B nanomodified resin [31]. Zappalorto et al. mentioned that the toughness improvements associated with nanomodification are strongly influenced by many factors, such as the filler morphology (size, geometry, and distribution) and, in particular, the applied loading conditions [32].

Vahedi and Pasbakhs revealed that 240\% improvement of impact toughness can be achieved by incorporating nanoclay into epoxy [33]. Most recently, Bhuvana and Prabakaran reported that the addition of nanoclay significantly increased storage modulus of polyamide up to $36 \%$ [34]. An improvement of Young's modulus up to $26 \%$ was reported by Gabr et al. [35] as well. Most of these studies agree that the incorporation of nanoclay into epoxy will increase its mechanical properties. Considering these reports, there are great prospects for nanoclay based materials since they are also becoming the subject of intense global research. Despite the abovementioned literatures on the mechanical properties of polymer nanocomposite, there is a need to investigate the effect of structure morphology and the seawater environmental effect

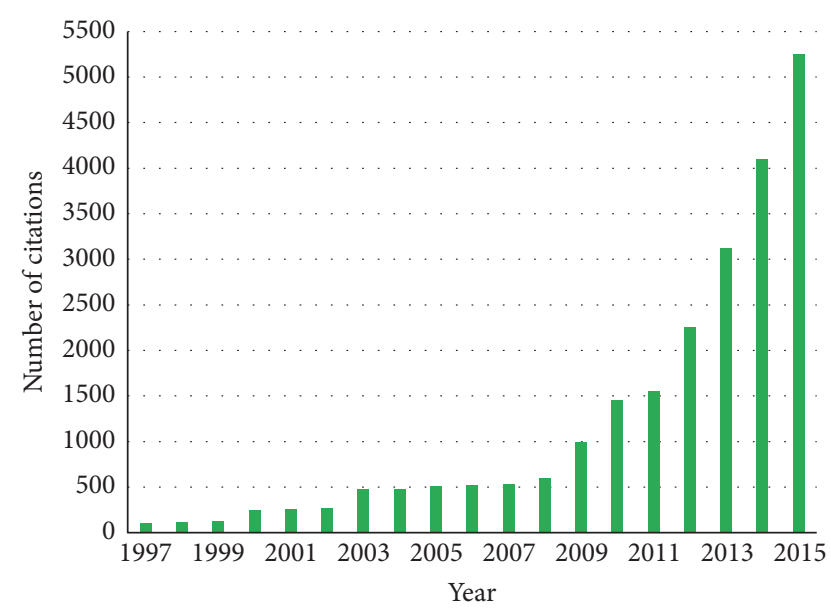

FIGURE 1: Number of citations using "halloysite" as keyword searched in title from the Web of Science (by 11/07/2016).

on the mechanical properties of polymer nanocomposites. This is due to the fact that the interaction between the seawater and polyester based nanocomposites is an issue that has not been sufficiently understood and analysed in the literature in a comprehensive manner. In fact, most of the previous studies were focused only on epoxy based polymers and some are rarely discussing the polyester based polymers exposed to seawater environment [3]. As the polyester based polymer is extensively used in aggressive marine environments, the long-term behaviour in such condition is still obscure. Further study is needed for thorough and clear evaluation of the maintenance period and total life time of polyester based polymer used in marine application as the effect of marine environment is complex and clearly depends on the compound used.

This study investigates the effect of nanoclay on the mechanical properties of polyester exposed to seawater environment. Figure 1 shows the increase in nanoclay research in recent years as the subject of the work is of interest both for the scientific community and for the industry. In many previous studies, it is noted that having uniform dispersion of nanoclay particularly in epoxy nanocomposites has remained a challenge [36]. Therefore, the authors hereby incorporated nanoclay at maximum $1 \mathrm{wt} \%$ reinforcement. This is based on a study carried out by Sancaktar and Kuznicki [37], where dispersing at higher weight fraction (more than $1 \mathrm{wt} \%$ clays) is difficult and agglomerated clay deteriorates the mechanical properties of the composite materials. Asadi et al. also found that the optimal clay reinforcement should be around $1 \mathrm{wt} \%$ for their epoxy-nanotubes nanocomposites samples [38].

\section{Materials}

Halloysite nanoclay was used as reinforcement filler and was acquired from Sigma-Aldrich (Figure 2(a)). The diameters are in between 30 and $70 \mathrm{~nm}$ with lengths between 1 and $4 \mu \mathrm{m}$. They possess tube-like morphologies as illustrated in Figure 2(b). The density of nanoclay is $2.53 \mathrm{~g} / \mathrm{cm}^{3}$ and surface 


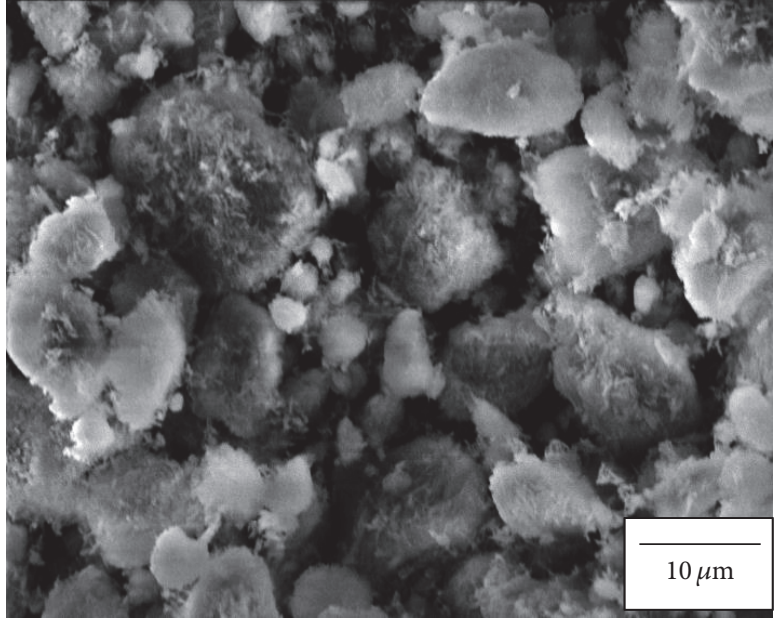

(a)

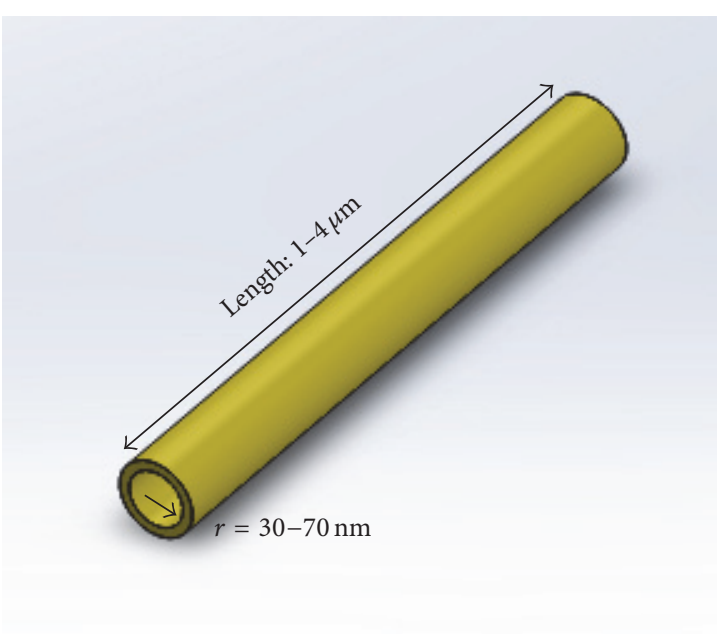

(b)

FIGURE 2: SEM images of halloysite nanoclay particles used in experiments as received (a) halloysite nanoclay in clusters and (b) schematic of halloysite nanoclay tubular structure.

area is $64 \mathrm{~m}^{2} / \mathrm{g}$. It has low electrical and thermal conductivities and strong hydrogen interactions. The tube-like morphology, high aspect ratio, and low percolation make nanoclay ideal reinforcement for polyester and other polymers.

The polyester resin (NORSODYNE O $12335 \mathrm{AL}$ ) was acquired from East Coast Fibreglass, UK. The resin has density of $1.2 \mathrm{~g} / \mathrm{cm}^{3}$. The catalyst (hardener) was methyl ethyl ketone peroxide solution in dimethyl phthalate and was purchased from East Coast Fibreglass, UK. To produce monolithic polyester samples, the resin was mixed with catalyst (Butanox M-50) with a polyester : catalyst ratio of $98: 2$. Following thorough hand mixing for 5 minutes, vacuum degassing was carried out for 5 minutes. The mixture was then poured into moulds and cured at room temperature for $24 \mathrm{~h}$ followed by postcuring at $60^{\circ} \mathrm{C}$ for $2 \mathrm{~h}$ according to a process performed by Bonnia et al. [39] and Ratna Prasad and Mohana Rao [40]. Four different weight fractions of nanoclay ( $0.1 \mathrm{wt} \%, 0.3 \mathrm{wt} \%, 0.7 \mathrm{wt} \%$, and $1.0 \mathrm{wt} \%)$ were used to reinforce the polyester. Collected seawater from South Shields, United Kingdom, was used to study the environmental effect on the polymer nanocomposites.

\section{Characterisation}

DMA (Model 8000, PerkinElmer) was used to determine dynamic storage modulus $\left(E^{\prime}\right)$ and loss modulus $\left(E^{\prime \prime}\right)$ of the samples. The loss factor $\tan \delta$ was calculated as the ratio $\left(E^{\prime \prime} / E^{\prime}\right)$. Rectangular test specimens of dimensions $20 \times 10 \times$ $3 \mathrm{~mm}$ were used with a single cantilever clamp. All tests were carried out by temperature sweep method (temperature ramp from $30^{\circ} \mathrm{C}$ to $130^{\circ} \mathrm{C}$ at $5^{\circ} \mathrm{C} \mathrm{min}{ }^{-1}$ ) at a constant frequency of $1 \mathrm{~Hz}$. The maximum force of DMA was $10 \mathrm{~N}$ and was applied during all the DMA test. The glass transition temperature $\left(T_{\mathrm{g}}\right)$ was taken as the temperature value at the peak of $\tan \delta$ curves. Scanning electron microscopy (SEM) analysis using
FEI Quanta 200 was carried out on the fractured surfaces of tensile specimens to evaluate the fracture modes in the samples. The fractured portions were cut from the specimens and a layer of gold was applied using Emscope sputter coater model SC500A.

Rectangular specimens with dimensions $80 \times 10 \times 4 \mathrm{~mm}$ were immersed into the liquid media at room temperature. The weight was measured after $168 \mathrm{~h}$ immersion using $0.001 \mathrm{mg}$ accurate weighing balance. Before weighing a specimen, any retained liquid (seawater) was removed from its surface with an absorbent paper. The samples were kept at room temperature for $168 \mathrm{~h}$ and increase in weight was measured every $24 \mathrm{~h}$ with respect to initial weight (before immersion). The seawater absorption in the sample was measured as \% weight increase in the samples. The following equation was used to calculate the seawater absorption in the specimens:

$$
W_{c}=\left(W_{t}-W_{o}\right) \times \frac{100}{W_{o}},
$$

where $W_{t}$ is the weight of specimen at time $t$ (i.e., after immersion in the liquid) and $W_{o}$ is the initial weight of the sample, that is, before placing in seawater. The specimens have been immersed in seawater and weighed at regular intervals of $24 \mathrm{~h}$ over a total time of $168 \mathrm{~h}$.

The densification of samples was calculated according to ASTM D792. The densities of polyester, hardener, nanoclay, and water were $1.2,1.18,2.53$, and $0.9975 \mathrm{~g} \mathrm{~cm}^{-3}$, respectively. The following equations were used to obtain the experimental density and densification:

Experimental density

$$
=\frac{\text { weight in air }}{\text { weight in air }- \text { weight in water }} \text {, }
$$




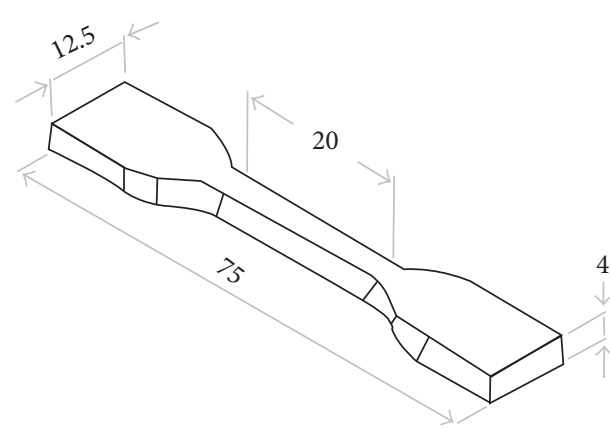

(a)

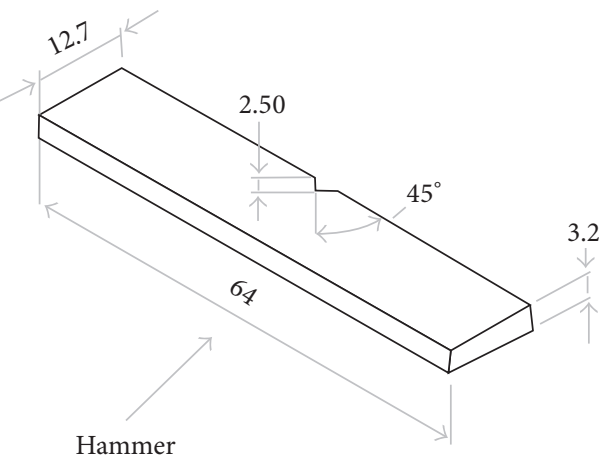

(c)

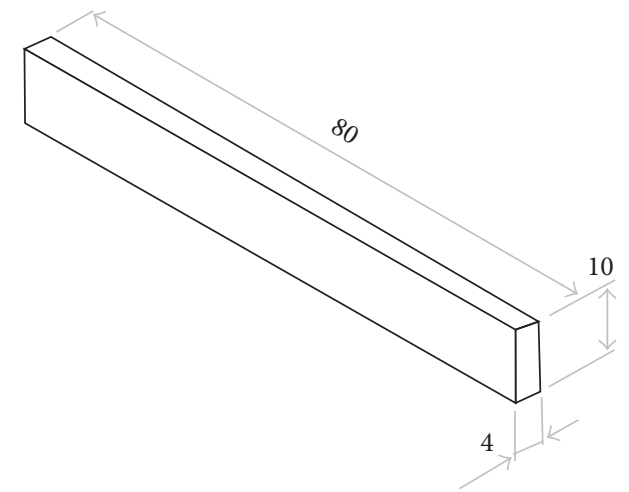

(b)

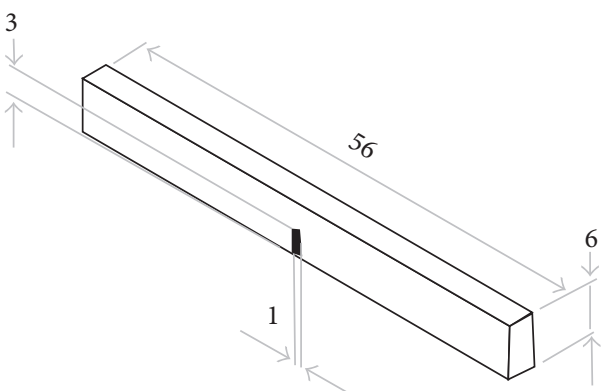

(d)

Figure 3: The schematic of specimens: (a) tensile, (b) flexural, and (c) Charpy impact toughness and (d) fracture toughness, $K_{\text {IC }}$.

\section{$\times$ density of water}

Densification $(\%)=\frac{\text { experimental density }}{\text { theoretical density }} \times 100$.

Vickers microhardness test was performed using the Buehler Micromet II for the monolithic polyester and its nanocomposites. The load applied was $200 \mathrm{~g}$ for 10 seconds. After seawater immersion, the samples were taken out and the liquid was completely wiped out from the specimen surface.

Tensile tests were performed using Instron Universal Testing Machine (Model 3382). Five specimens were tested for each composition. The displacement rate was kept at $1 \mathrm{~mm} / \mathrm{min}$. Tensile properties were assessed according to ISO 527 (Figure 3(a)) with specimen thickness of $3 \mathrm{~mm}$. Threepoint bending test was performed according to ISO 178 with dimensions $80 \times 10 \times 4 \mathrm{~mm}$ (Figure 3(b)).

Charpy impact toughness test was performed according to ASTM D6110 (Figure 3(c)) using notch samples. A notch of $45^{\circ}$ was made in the centre of the samples. The impact toughness was obtained using (3), where $m$ is mass of hammer $(\mathrm{kg}), g$ is standard gravity $\left(9.81 \mathrm{~m} \mathrm{~s}^{-2}\right), h$ is the length of hammer $(\mathrm{m})$, and $t$ is sample thickness $(\mathrm{mm})$. Hence,

$$
\text { Impact toughness }=\frac{m g h(\cos \beta-\cos \alpha)}{w t} .
$$

Fracture toughness $\left(K_{\mathrm{IC}}\right)$ was determined using a single edge notch three-point bending (SEN-TPB) specimen (ASTM D5045) as shown in Figure $3(d)$. The dimensions were $3 \times$ $6 \times 36 \mathrm{~mm}$ with a crack length of $3 \mathrm{~mm}$ at the middle of the sample. $K_{\text {IC }}$ was calculated using linear fracture mechanics by the following relationship:

$$
K_{\mathrm{IC}}=\frac{P_{\max }(a / w)}{\mathrm{BW}^{1 / 2}}
$$

where $f(a / w)$ is the calibration factor for the samples which is given as

$$
f\left(\frac{a}{w}\right)=\frac{\left[(2+a / w)\left\{0.0866+4.64(a / w)^{2}+14.72(a / w)^{3}-5.6(a / w)^{4}\right\}\right]}{(1-a / w)^{3 / 2}}
$$




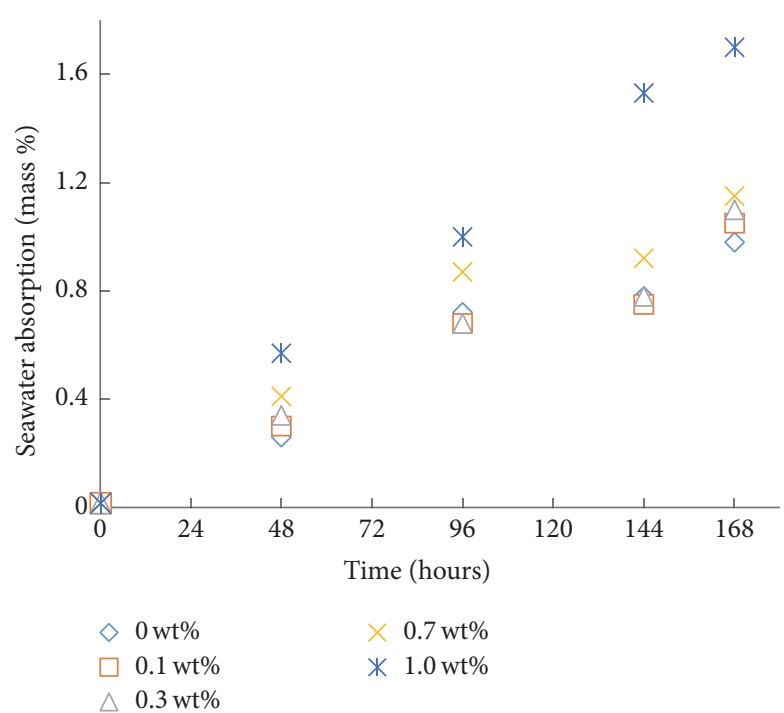

FigURE 4: Absorption behaviour of nanoclay-polyester nanocomposites.

The critical strain energy release rate $\left(G_{\text {IC }}\right)$ was obtained using (6) where $E$ is Young's modulus calculated from the tensile tests (MPa) and $v$ is Poisson's ratio of the polyester, taken to be 0.35 . Hence,

$$
G_{\mathrm{IC}}=\frac{K_{\mathrm{IC}}}{E}\left(1-v^{2}\right)
$$

\section{Results and Discussion}

Seawater absorption analyses are shown in Figure 4. In case of $0.3 \mathrm{wt} \%$ reinforcement, the seawater absorption was $0.12 \%$ higher compared to monolithic polyester after $168 \mathrm{~h}$ of immersion. At $1 \mathrm{wt} \%$ reinforcement, the seawater absorption was $0.72 \%$ more than that of monolithic polyester. Higher nanoclay content contributes to more seawater diffusion by swelling matrix and nanoparticles. The seawater absorption was found to increase as the nanoclay increased. Seawater molecules may enter through polymer chain and microvoids. A study by Dhakal et al. also revealed a similar trend of absorption in polyester nanocomposites [41]. The increased amount of spaces between nanoclay particles created an abundant surface area on which water molecules can adhere. Due to its high surface area, the nanoclay absorbed more seawater than unfilled polyester. On the other hand, several authors revealed that the water absorption of clay-polymers matrix nanocomposites is mainly influenced by two aspects. The first suggests that the clay body is water rich and thus absorbs more liquid than nearly all the polymers used as matrix [42]. The second one states that clay layers dispersed in the nanoscale are able to decrease the mean free path of water molecules to pass through the nanocomposite network compared to monolithic matrix. As a result, this reduces water absorption [33,34]. This research however is in line with what has been reported by Ollier et al. where the clay absorbed seawater more than unfilled polyester [42].

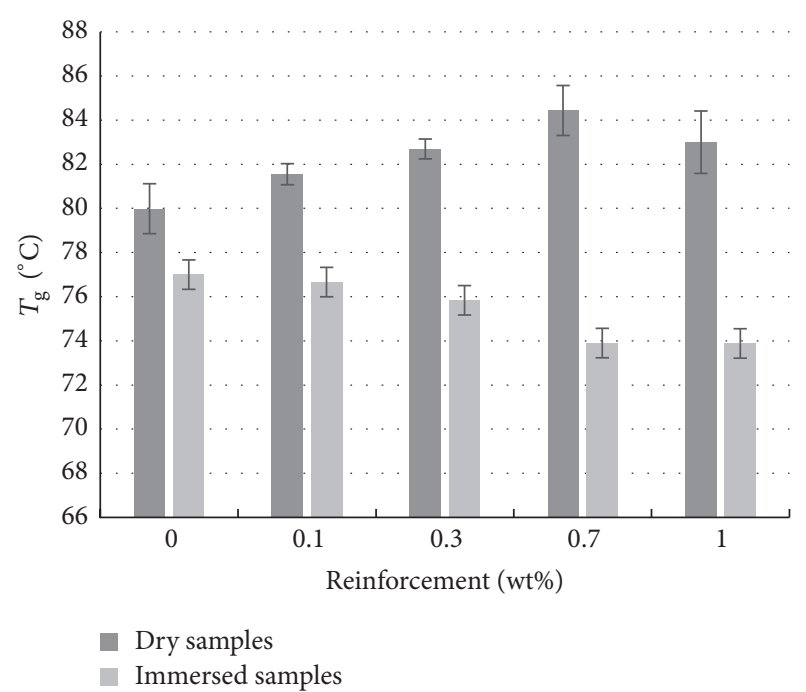

FIGURE 5: $T_{\mathrm{g}}$ of nanocomposites for dry and immersed samples.

4.1. Results and Discussion of the Experiments. The DMA results are shown in Figures 5, 6, and 7. The changes in $T_{\mathrm{g}}$ depend on the percentage of filler incorporated. In dry condition, the halloysite nanoclay remarkably increased $T_{\mathrm{g}}$. In case of monolithic polyester, the mean value of $T_{\mathrm{g}}$ was $80^{\circ} \mathrm{C}$. The $T_{\mathrm{g}}$ values were found to steadily increase as nanoclay increased. For instance, in case of $0.7 \mathrm{wt} \%$, an increase of $4.4^{\circ} \mathrm{C}$ in $T_{\mathrm{g}}$ was recorded. However, in case of $1 \mathrm{wt} \%$ reinforcement, the $T_{\mathrm{g}}$ value was slightly lower than nanocomposites of $0.7 \mathrm{wt} \%$ reinforcement $\left(3^{\circ} \mathrm{C}\right.$ increase compared to monolithic polyester). This phenomenon is due to the agglomeration of halloysite nanoclay particles where these particles tend to form clay clusters or platelets as also reported by Liu et al. [43].

After seawater immersion, it was observed that the $T_{\mathrm{g}}$ values dropped considerably in comparison to dry conditions. The seawater undoubtedly had altered the structural integrity of the nanocomposites. Samples immersed in seawater were found to swell and to be slightly soft compared to samples tested in the dry condition. After seawater immersion, monolithic polyester recorded the highest $T_{\mathrm{g}}$ value of $77^{\circ} \mathrm{C}$. The minimum $T_{\mathrm{g}}$ value was observed in case of $1 \mathrm{wt} \%\left(74^{\circ} \mathrm{C}\right)$ nanoclay reinforcement. The decrease in $T_{\mathrm{g}}$ with nanoclay addition could be attributed to the plasticization effect on the matrix by the organic modifier of the nanoclay. The plasticization may have also been caused by the slipping of nanoclay platelets in the clustered nanoclay [44]. The storage modulus and loss modulus of the polyester and its nanocomposites in dry condition are shown in Figures $6(\mathrm{a})$ and $7(\mathrm{a})$. The storage and loss moduli data were taken from the highest peak of $\tan \delta$. The storage moduli were higher at initial temperature $\left(30^{\circ} \mathrm{C}\right)$ and then decreased when approaching $T_{\mathrm{g}}$. It can be found that the increase in stiffness and restriction in the movement of polymer chains by halloysite nanoclay caused remarkable improvement in storage modulus of the nanocomposites.

Very little increase in storage modulus was recorded in case of $0.1 \mathrm{wt} \%$ reinforcement (162\% increase). The highest 


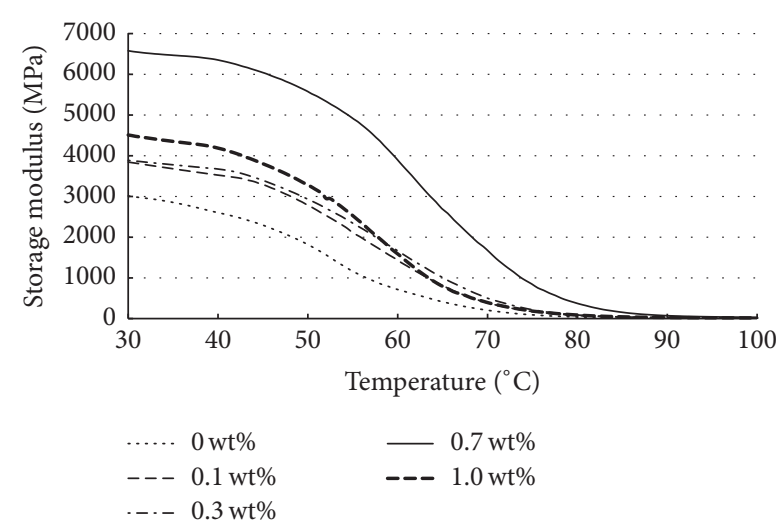

(a)

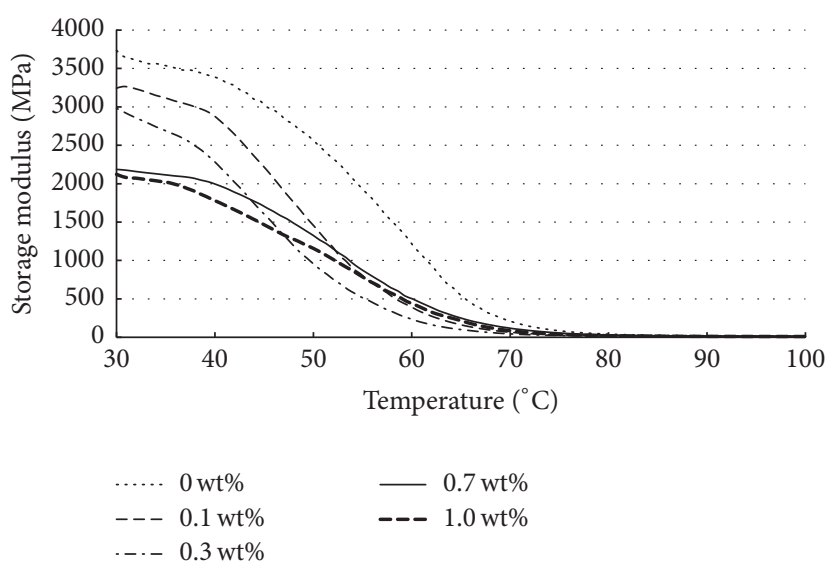

(b)

FIGURE 6: Storage modulus of dry (a) and immersed (b) samples.

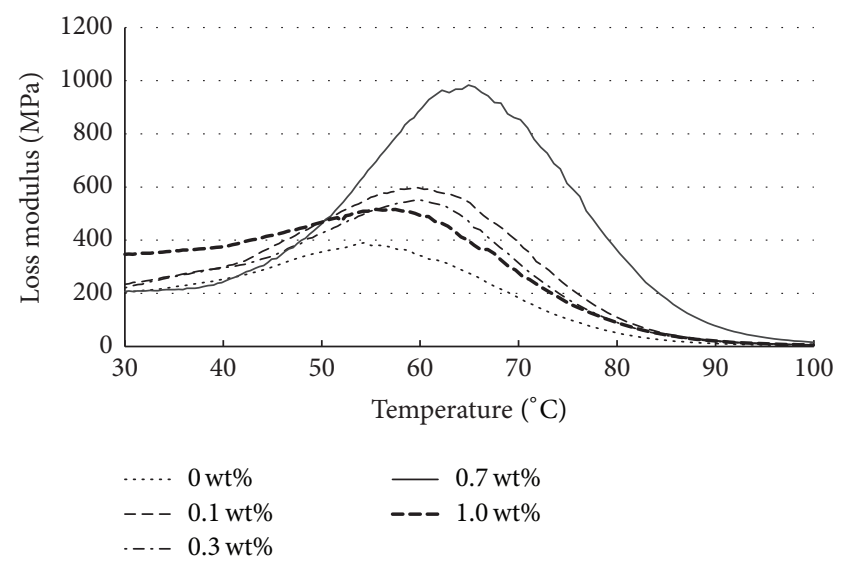

(a)

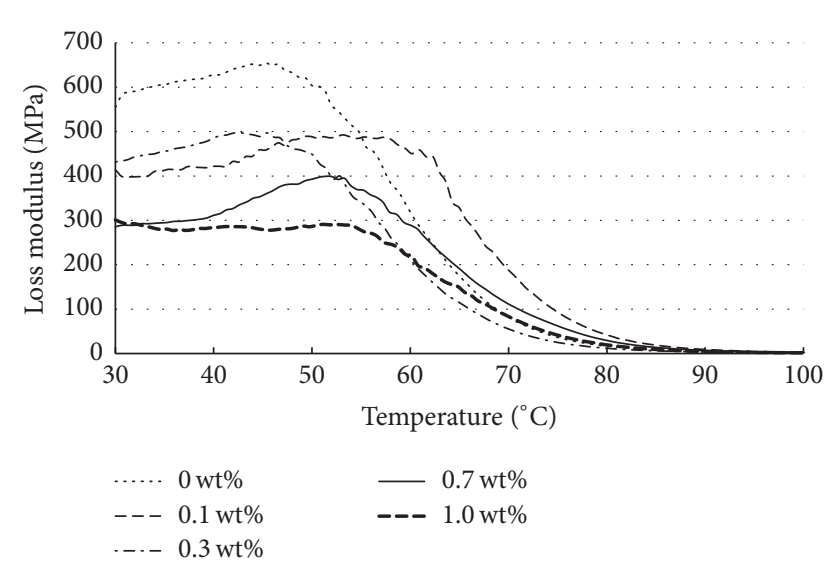

(b)

FIGURE 7: Loss modulus of nanocomposites in air (a) and after seawater exposure (b).

increase of storage modulus was observed in case of $0.7 \mathrm{wt} \%$ with a $678 \%$ increase. After seawater exposure, different trends were observed. The seawater environment reduced the stiffness of the samples especially for the nanocomposites systems. About 27\% storage modulus decrease was observed in case of $0.7 \mathrm{wt} \%$. The maximum decrease of storage modulus was $43 \%$ in case of $1 \mathrm{wt} \%$ reinforcement.

Based on the dynamic mechanical analysis, it is evidently shown that monolithic polyester shows better resistance towards the seawater environment. Loss modulus of the polyester and nanocomposites is shown in Figure 7(b). The curves for all nanocomposites systems were found to shift slightly to the left compared to samples tested in the dry condition. Apart from that, it can be seen from the figure that the loss modulus peak values decrease when samples were immersed in seawater.

After seawater immersion, monolithic polyester had the highest loss modulus curve followed by $0.1 \mathrm{wt} \%, 0.3 \mathrm{wt} \%$, $0.7 \mathrm{wt} \%$, and $1 \mathrm{wt} \%$ reinforcement. The significant decrease of loss modulus was from $555 \mathrm{MPa}$ to $295 \mathrm{MPa}$ ( $1 \mathrm{wt} \%$ reinforcement). The samples exposed to seawater for longer periods are softer than the dried samples. The water-absorbed samples tend to be less stiff than the dried samples.

The densification percentage of nanoclay-polyester nanocomposites is presented in Figure 8(a). The large standard deviations in the nanocomposites can be attributed to the porosity in the samples produced. Entrapped air bubbles in the resin restricted the movement of the polymer chains and acted as micropores after curing [45]. Another mechanism for their existence is due to the relative fast curing of polyester resin when mixed with curing agent, where the volatiles could not escape during the exothermic curing process.

Surface hardness is normally investigated as one of the most important factors that are related to the abrasion and wear resistance of nanocomposites materials [39, 40]. The Vickers microhardness graph is shown in Figure 8(b) for samples tested in air and after seawater exposure. The incorporation of nanoclay significantly improved the microhardness property, particularly in case of $0.7 \mathrm{wt} \%$ reinforcement (44\% increase). Minimum microhardness improvement was observed in case of $0.1 \mathrm{wt} \%$ with $11.4 \%$ increase. After seawater immersion, monolithic polyester showed maximum 

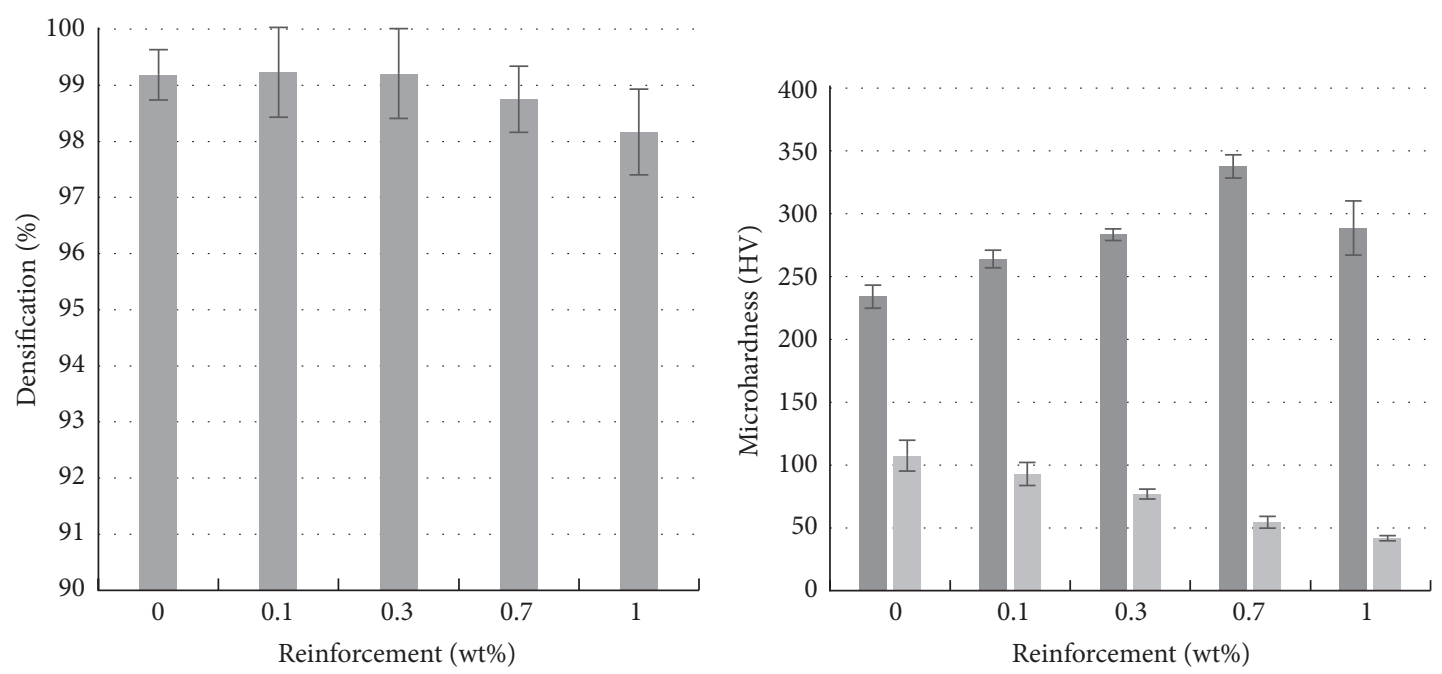

Dry samples

- Immersed samples

(a)

(b)
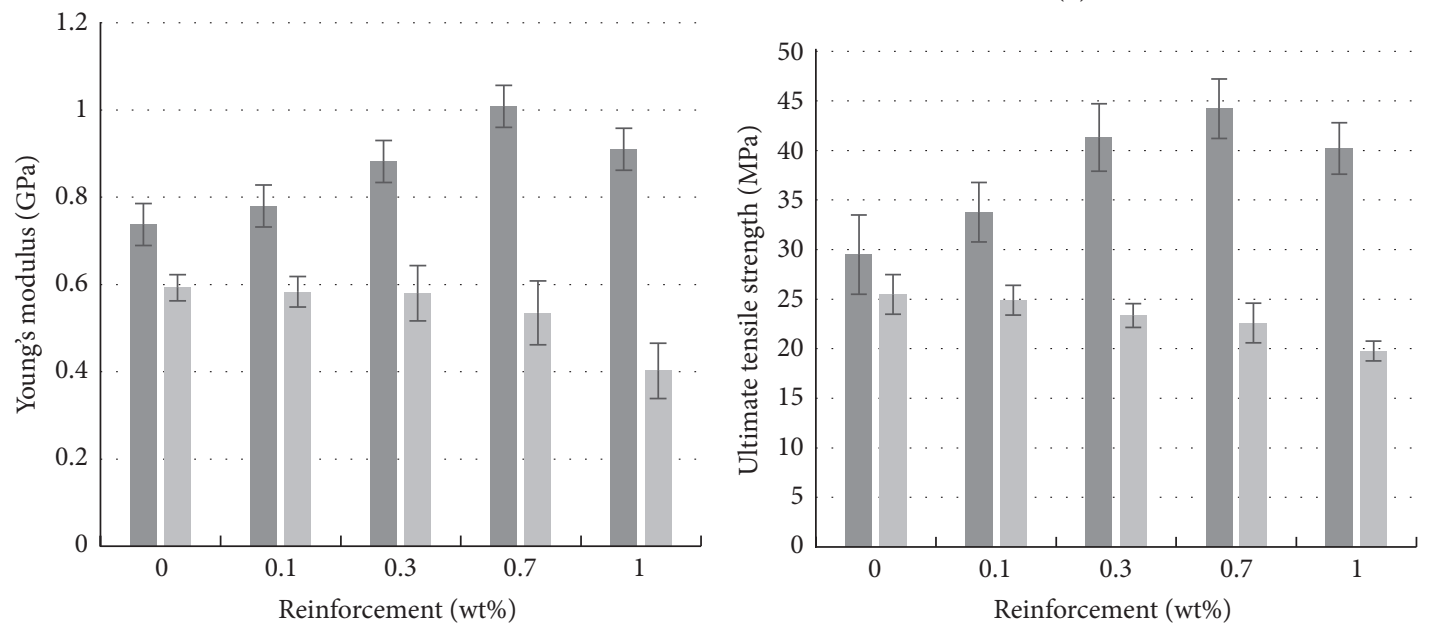

Dry samples

- Immersed samples

- Dry samples

Immersed samples

(c)

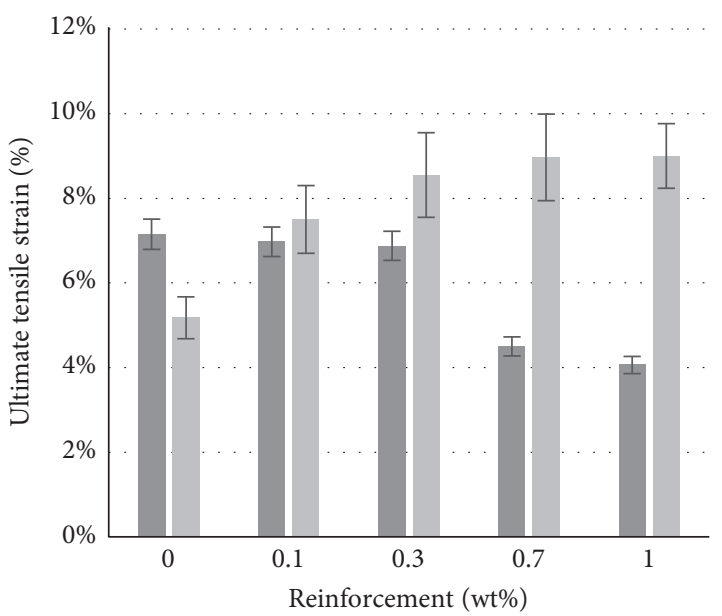

(d)

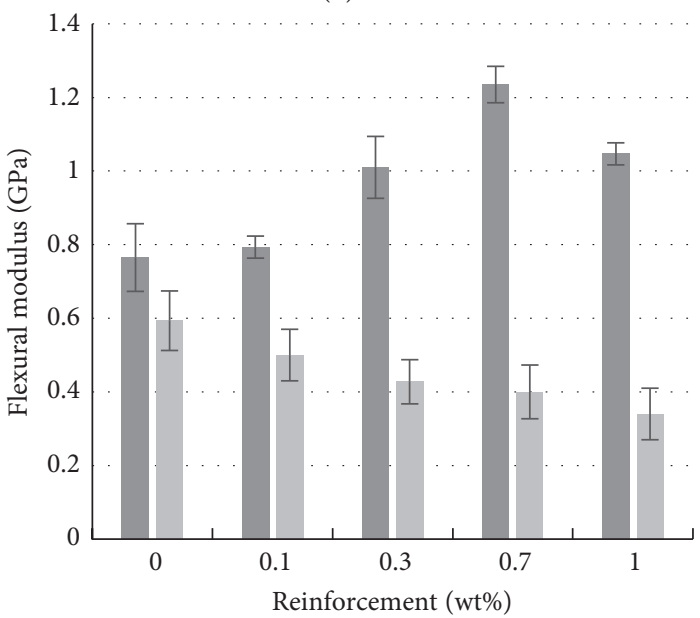

- Dry samples

- Dry samples

Immersed samples

Immersed samples

(e)

Figure 8: Continued. 


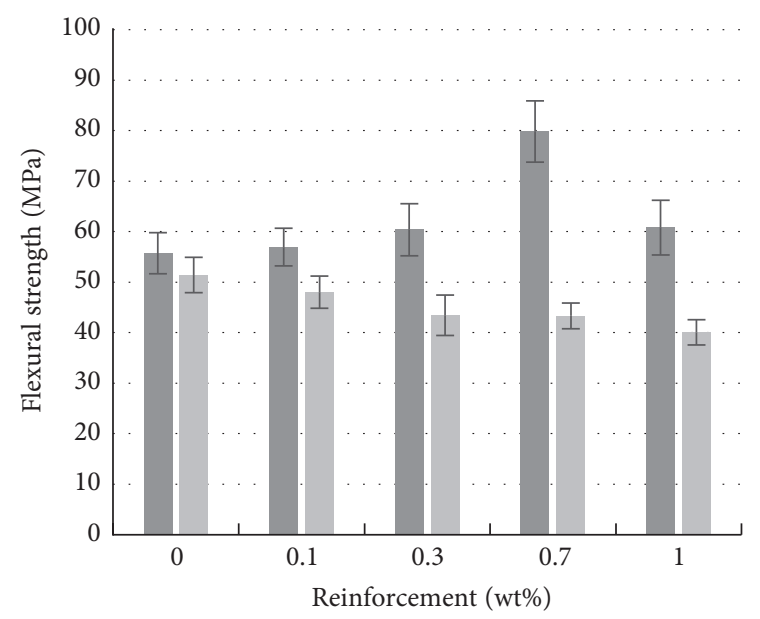

Dry samples
Immersed samples

(g)

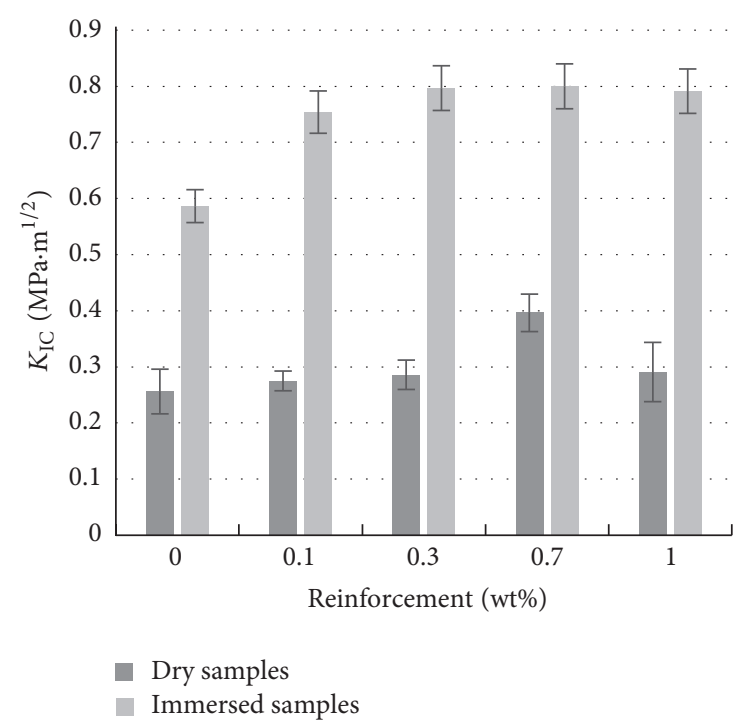

(i)

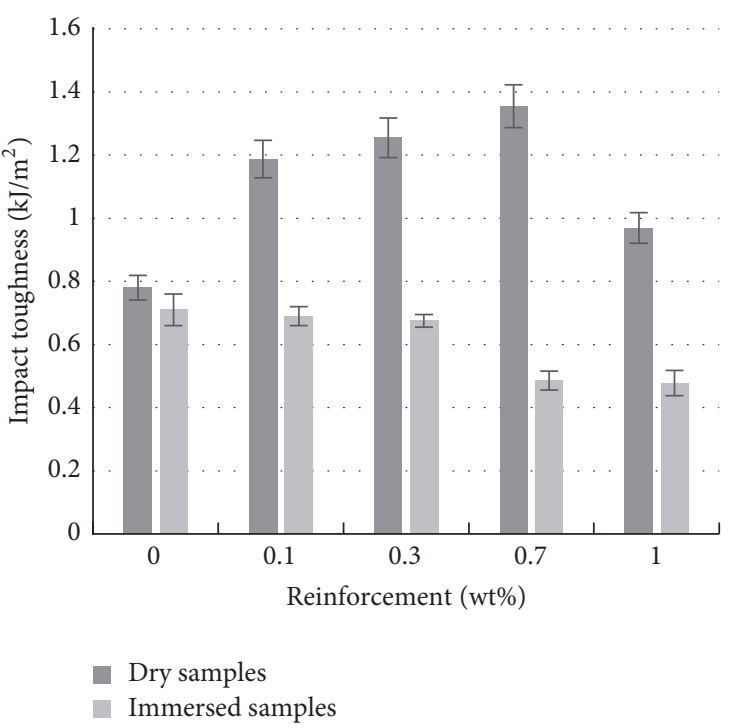

(h)

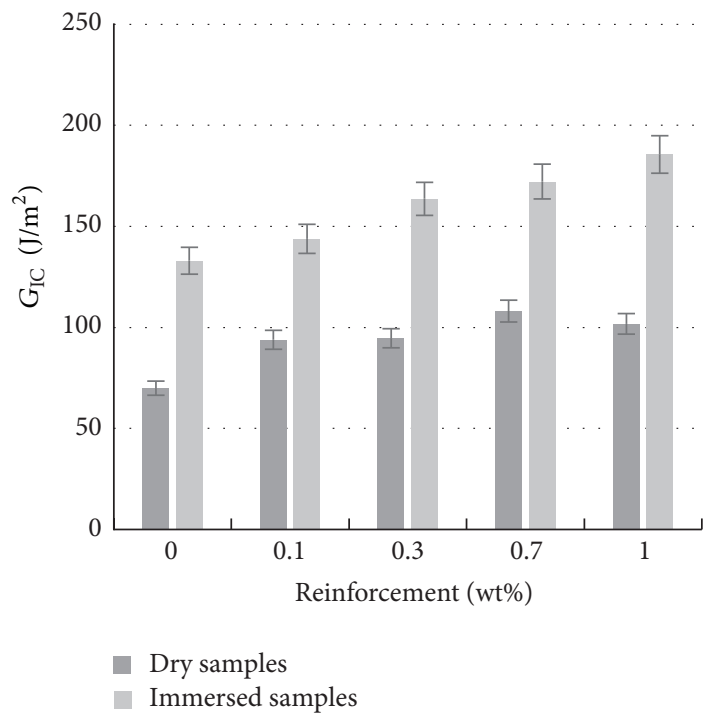

(j)

FIGURE 8: Mechanical properties of halloysite nanoclay-polyester nanocomposites in dry and wet conditions.

hardness, while at $1 \mathrm{wt} \%$ reinforcement the lowest value of microhardness was recorded (61\% reduction).

Young's moduli (tensile moduli) of the monolithic polyester and its composites are shown in Figure 8(c). Monolithic polyester recorded the lowest Young modulus of $0.7 \mathrm{GPa}$. The minimum increase for Young's modulus was observed in case of $0.1 \mathrm{wt} \%$ with $5.4 \%$ improvement. The nanoclay also showed the maximum increase of $35 \%$ in case of $0.7 \mathrm{wt} \%$ reinforcement. Significant Young's modulus reduction can be seen after seawater immersion. At $1 \mathrm{wt} \%$ nanoclay reinforcement, Young's modulus dropped from $0.6 \mathrm{GPa}$ to $0.4 \mathrm{GPa}$ (33.3\% decrease).

The UTS (ultimate tensile strength) is presented in Figure $8(\mathrm{~d})$. The maximum increase in UTS was from $29.5 \mathrm{MPa}$ to $44.2 \mathrm{MPa}$ ( $50 \%$ increase) in case of $0.7 \mathrm{wt} \%$ nanoclay. The nanoclay also showed a minimum increase up to $15.3 \%$ in case of $0.1 \mathrm{wt} \%$ reinforcement. After seawater exposure, the UTS showed a significant decrease. The maximum decrease of UTS was observed in case of $1.0 \mathrm{wt} \%$ reinforcement $(22 \%$ decrease) compared to monolithic polyester. The nanoclay likewise showed minimum decrease up to $2.4 \%$ in case of $0.1 \mathrm{wt} \%$ reinforcement.

The variation in ultimate tensile strain (\%) is shown in Figure $8(\mathrm{e})$. The tensile strain was obtained from the $\%$ value of strain corresponding to UTS. In dry conditions, the reinforcement of nanoclay reduced the tensile strain. This is due to the fact that the nanoclay reinforcement improved the stiffness of the nanocomposites materials. In case of $0.7 \mathrm{wt} \%$ reinforcement, the ultimate tensile strain was $4.5 \%$. This lower strain value can be attributed to the stiffness of the nanocomposites. After seawater immersion, the ultimate tensile strain values were increased for all nanocomposites as a result of 
the plasticization effect. About $5.2 \%$ of the tensile strain value was observed for monolithic polyester. In contrast, at $1 \mathrm{wt} \%$ reinforcement, $9 \%$ of the tensile strain was observed. The increase of tensile strain is due to the softening of the polymer matrix which increased the energy required to create a fracture. Reductions in the tensile properties (ultimate tensile strength, Young's modulus, and ultimate tensile strain) can be associated with the plasticization effect of the resin matrix by seawater, which appears to lower the yield stress and increase the size of the plastic zone ahead of the crack [41, 42, 46]. Apart from that, the weakening of adhesion between halloysite nanoclays and matrix is also the reason of the decrease in tensile properties [47]. As for the flexural modulus (Figure $8(\mathrm{f})$ ), nanocomposites samples tested in air condition showed excellent improvements. Maximum flexural modulus was achieved at $0.7 \mathrm{wt} \%$ reinforcement from $0.77 \mathrm{GPa}$ to $1.24 \mathrm{GPa}$ (61\% improvement). In wet conditions, the flexural modulus dropped from $0.6 \mathrm{GPa}$ (monolithic polyester) to $0.34 \mathrm{GPa}$ ( $1 \mathrm{wt} \%$ nanoclay). The variations of flexural strength are shown in Figure $8(\mathrm{~g})$. The maximum flexural strength was observed from $55.7 \mathrm{MPa}$ to $80 \mathrm{MPa}$ in case of $0.7 \mathrm{wt} \%(44 \%$ increase). About 2.3\% increase was obtained at $0.1 \mathrm{wt} \%$ reinforcement. A similar trend was also found in samples exposed to seawater where the flexural strength dropped significantly. In case of $1 \mathrm{wt} \%$, it can be seen that the flexural strength was reduced by about $22 \%$. Monolithic polyester, in contrast, showed the maximum flexural strength value which is 51.4 MPa.

The variations of impact toughness results are shown in Figure 8(h). Samples tested in dry conditions showed that the Charpy impact toughness remarkably increased and the minimum improvement was observed at $0.1 \mathrm{wt} \%$ (54\% increase). The impact toughness increased steadily and reached maximum values at $0.7 \mathrm{wt} \%$ reinforcement ( $80 \%$ increase). The seawater exposure reduced the impact strength of the nanocomposites. The increase of impact toughness can be attributed to the good interfacial adhesion between nanoclay and the polyester matrix. Good interfacial bonding between nanoclay and polyester requires higher energy absorbing capacity, which as a result produces higher impact strength. This finding is in agreement with Albdiry et al. [48] and Lin et al. [49] who reported maximum improvements in impact toughness of $61 \%$ and $300 \%$, respectively. However, after seawater immersion, the impact strength for the nanocomposites was decreased. The impact strength decreased by $9 \%$ in case of $0.1 \mathrm{wt} \%$ reinforcement. The lowest impact toughness was observed in case of $1 \mathrm{wt} \%$, with $32 \%$ decrease.

The $K_{\text {IC }}$ and $G_{\text {IC }}$ values are presented in Figures 8(i) and $8(j)$, respectively. It can be observed that $K_{\text {IC }}$ and $G_{\text {IC }}$ monotonically increased with the increase of halloysite nanoclays addition (from $0.1 \mathrm{wt} \%$ to $0.7 \mathrm{wt} \%$ ). For dry samples, the maximum increase of $K_{\text {IC }}$ was obtained in case of $0.7 \mathrm{wt} \%$ from 0.26 to $0.4 \mathrm{MPa} \cdot \mathrm{m}^{1 / 2}$ (54\% increase). For the nanocomposites immersed in seawater, $K_{\mathrm{IC}}$ also increased with the increase in halloysite nanoclay loading due to liquid absorption which caused plasticization of polymer matrix. The maximum $K_{\text {IC }}$ after seawater immersion was obtained in case of $1 \mathrm{wt} \%$ reinforcement from $0.59 \mathrm{MPa} \cdot \mathrm{m}^{1 / 2}$ to $0.79 \mathrm{MPa} \cdot \mathrm{m}^{1 / 2}(34 \%$ increase). The maximum $G_{\text {IC }}$ recorded for dry samples was observed in case of $0.7 \mathrm{wt} \%$ from $70 \mathrm{~J} / \mathrm{m}^{2}$ to $108 \mathrm{~J} / \mathrm{m}^{2}(54.3 \%$ increase). After seawater immersion, samples with $1 \mathrm{wt} \%$ halloysite nanoclay reinforcement recorded the maximum $G_{\text {IC }}$ from $133 \mathrm{~J} / \mathrm{m}^{2}$ to $185 \mathrm{~J} / \mathrm{m}^{2}$ (39\% increase). The seawater uptake caused the polymer matrix to soften and increase the ductility of the samples; as a result, the failure time also increased.

4.2. SEM Images. Figures 9(a), 9(b), 9(c), 9(d), and 9(e) show the fractured surface of the monolithic polyester and its nanocomposites exposed in seawater environment. The fractured surface layers are short and round ended in monolithic polyester showing minimal plastic deformation. The monolithic polyester samples also showed the roughest surface compared to halloysite nanoclay-polyester nanocomposites. The surface roughness corresponds to the resistance of the material to the propagation of the cracks. It can be observed from the figure that the morphological structures of nanocomposites based on reinforcement polyester resin with halloysite nanoclay particles prepared are uniformly dispersed especially in case of $0.1 \mathrm{wt} \%, 0.3 \mathrm{wt} \%$, and $0.7 \mathrm{wt} \%$. In case of $1 \mathrm{wt} \%$ reinforcement, agglomeration can be seen as shown in Figure 9(e).

The fracture mode on halloysite nanoclay-polyester nanocomposites was a smooth, straight path and showed a sign of plastic deformation. When the crack initiates, it propagates with fewer diversions and more likely results in straight fracture paths or river markings. Lower resistance to crack propagation shows more straight and longer fracture paths as shown in Figure 9(e).

Agglomeration of halloysite nanoclays can be seen in $1 \mathrm{wt} \%$ reinforcement also shown in Figure 9(e). The halloysite nanoclay clusters were found to be poorly dispersed. This also proves that at high concentration the movement of clay is restricted. The agglomeration of nanoparticles and the plasticization effect are important factors affecting the final properties of the nanocomposites at $1 \mathrm{wt} \%$ reinforcement.

\section{Conclusions}

The results showed that small amounts of nanoclay considerably improved the microhardness, tensile properties, flexural properties, impact toughness, and fracture toughness of the nanocomposites. In dry conditions, the optimal limit of nanoclay was found in case of $0.7 \mathrm{wt} \%$. The microhardness was improved by $44 \%$ compared to monolithic polyester. Young's modulus increased from $0.7 \mathrm{GPa}$ to $1 \mathrm{GPa}(43 \%$ increase) and the flexural modulus increased from $0.77 \mathrm{GPa}$ to $1.24 \mathrm{GPa}$ (61\% increase). The fracture toughness improved from $0.26 \mathrm{MPa} \cdot \mathrm{m}^{1 / 2}$ to $0.4 \mathrm{MPa} \cdot \mathrm{m}^{1 / 2}$ (54\% increase).

The seawater exposure, however, has significantly reduced the mechanical properties of the nanocomposites. The microhardness decreased from $107 \mathrm{HV}$ to $42 \mathrm{HV}$ (61\% decrease) compared to monolithic polyester. Young's modulus exhibited a decrease of $33 \%$, and flexural modulus exhibited a decrease of $43 \%$. The maximum $K_{\text {IC }}$ after seawater immersion was obtained in case of $1 \mathrm{wt} \%$ reinforcement from $0.59 \mathrm{MPa} \cdot \mathrm{m}^{1 / 2}$ to $0.79 \mathrm{MPa} \cdot \mathrm{m}^{1 / 2}$ (34\% increase). Maximum 


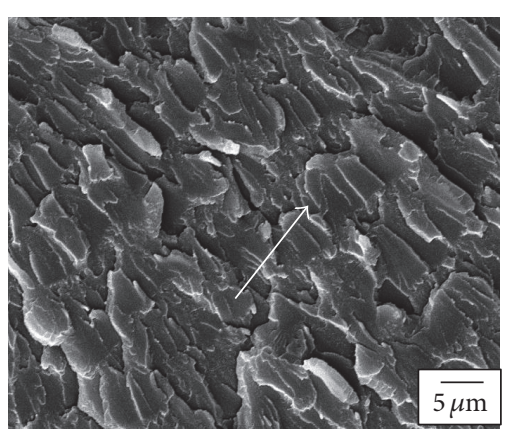

(a)

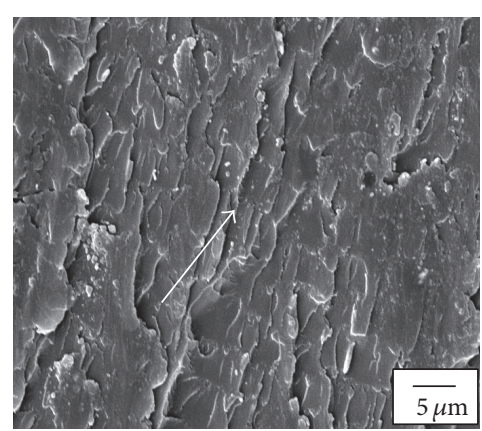

(b)

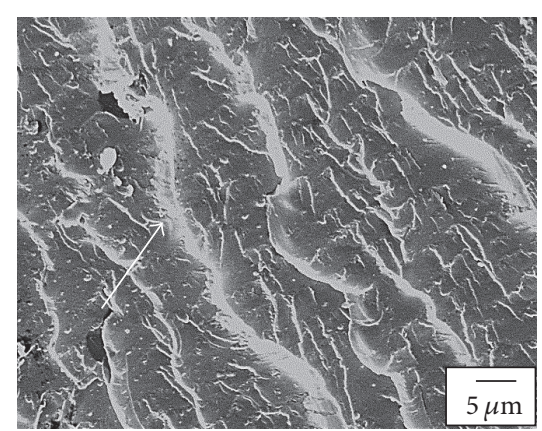

(c)

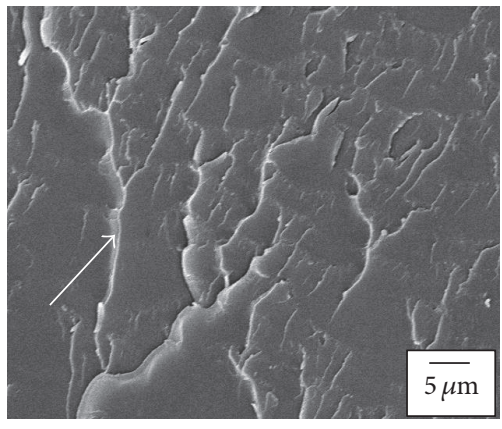

(d)

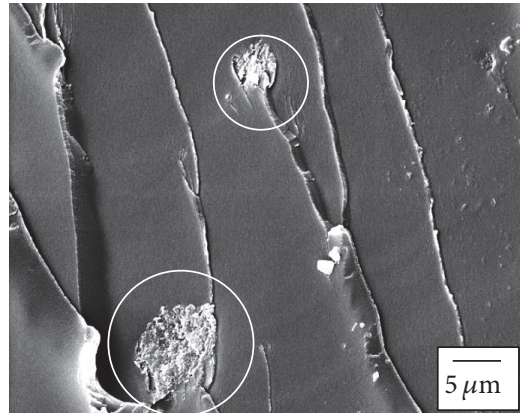

(e)

FIGURE 9: SEM images showing the details of fracture surfaces of polyester and its nanocomposites; (a) monolithic polyester, (b) $0.1 \mathrm{wt} \%$ reinforcement polyester, (c) $0.3 \mathrm{wt} \%$ reinforcement, (d) fractured surface of $0.7 \mathrm{wt} \%$ reinforcement, and (e) fractured surface of $1 \mathrm{wt} \%$ reinforcement.

$G_{\text {IC }}$ was obtained from $133 \mathrm{~J} / \mathrm{m}^{2}$ to $185 \mathrm{~J} / \mathrm{m}^{2}$ (39\% increase). The seawater uptake caused the polymer matrix to soften and increase the ductility of the samples; as a result, the failure time also increased.

During the water immersion tests of the nanocomposites, the interface alone or possibly both the interface and the nanoparticles were damaged and caused degradation of nanocomposites properties. This can be attributed to poor interfacial adhesion between the nanoclay and polymer matrix. On the other hand, the seawater diffusion in nanocomposites depends on several issues such as the volume of the fillers as well as the viscosity of the matrix. The halloysite nanoclay increased the viscosity and is likely to produce voids in the nanocomposites. Voids allow seawater to diffuse easily. The interfacial region in nanoclay-polyester nanocomposites is more susceptible to damage due to seawater absorption. Microhardness, tensile properties, flexural properties, and impact toughness were significantly negatively affected by seawater immersion after $168 \mathrm{~h}$.

\section{Competing Interests}

The authors declare that they have no competing interests.

\section{Acknowledgments}

The authors wish to thank Majlis Amanah Rakyat (MARA), Malaysia, for the financial support in this research project and Northumbria University for the research facilities provided.

\section{References}

[1] M. S. Saharudin, I. Shyha, and F. Inam, "Viscoelastic and mechanical properties of multi-layered-graphene polyester composites," in Proceedings of the 2nd International Conference on Advances in Mechanical Engineering (ICAME '16), pp. 41-45, Istanbul, Turkey, 2016.

[2] W. Han, S. Chen, J. Campbell, X. Zhang, and Y. Tang, "Fracture toughness and wear properties of nanosilica/epoxy composites under marine environment," Materials Chemistry and Physics, vol. 177, pp. 147-155, 2016.

[3] M. S. Saharudin, R. Atif, I. Shyha, and F. Inam, “The degradation of mechanical properties in polymer nano-composites exposed to liquid media-a review," RSC Advances, vol. 6, no. 2, pp. 10761089, 2016.

[4] J. P. Pascault and R. J. J. Williams, "Thermosetting polymers," in Handbook of Polymer Synthesis, Characterization, and Processing, pp. 519-533, 2013.

[5] P. Bordes, E. Pollet, and L. Avérous, "Nano-biocomposites: biodegradable polyester/nanoclay systems," Progress in Polymer Science, vol. 34, no. 2, pp. 125-155, 2009.

[6] J. K. Fink, "Unsaturated polyester resins," in Reactive Polymers Fundamentals and Applications, pp. 1-67, 2008.

[7] R. J. Young and P. A. Lovell, Introduction to Polymers, CRC Press, 2011.

[8] J. Thomason, Glass Fibre Sizings: a Review of the Scientific Literature, Kindle, Amazon Media EU, Seattle, Wash, USA, 2012.

[9] H. M. Akil, C. Santulli, F. Sarasini, J. Tirillò, and T. Valente, "Environmental effects on the mechanical behaviour of pultruded jute/glass fibre-reinforced polyester hybrid composites," Composites Science and Technology, vol. 94, pp. 62-70, 2014. 
[10] F. Inam and N. Luhyna, "Carbon nanotubes for epoxy nanocomposites: a review on recent developments," in Proceedings of the 2nd International Conference on Advanced Composite Materials and Technologies for Aerospace Applications, Wrexham, UK, June 2012.

[11] J. Gustin, A. Joneson, M. Mahinfalah, and J. Stone, "Low velocity impact of combination Kevlar/carbon fiber sandwich composites," Composite Structures, vol. 69, no. 4, pp. 396-406, 2005.

[12] R. Atif, J. Wei, I. Shyha, and F. Inam, "Use of morphological features of carbonaceous materials for improved mechanical properties of epoxy nanocomposites," RSC Advances, vol. 6, no. 2, pp. 1351-1359, 2016.

[13] R. Atif, I. Shyha, and F. Inam, "The degradation of mechanical properties due to stress concentration caused by retained acetone in epoxy nanocomposites," RSC Advances, vol. 6, no. 41, pp. 34188-34197, 2016.

[14] M. S. Saharudin, A. Jumahat, A. Z. A. Kahar, and S. Ahmad, "The influence of alumina filler on impact properties of short glass fiber reinforced epoxy," Applied Mechanics and Materials, vol. 393, pp. 88-93, 2013.

[15] M. Zappalorto, M. Salviato, A. Pontefisso, and M. Quaresimin, "Notch effect in clay-modified epoxy: a new perspective on nanocomposite properties," Composite Interfaces, vol. 20, no. 6 , pp. 405-419, 2013.

[16] M. S. Saharudin, R. Atif, I. Shyha, and F. Inam, "The degradation of mechanical properties in halloysite nanoclay-polyester nanocomposites exposed to diluted methanol.," Journal of Composite Materials, 2016.

[17] Y. Ye, H. Chen, J. Wu, and L. Ye, "High impact strength epoxy nanocomposites with natural nanotubes," Polymer, vol. 48, no. 21, pp. 6426-6433, 2007.

[18] M. S. Saharudin, I. Shyha, and F. Inam, “The effect of methanol exposure on the flexural and tensile properties of halloysite nanoclay polyester," in Proceedings of the IRES 17th International Conference, pp. 40-44, November 2015.

[19] R. Kamble, M. Ghag, S. Gaikawad, and B. K. Panda, "Review article halloysite nanotubes and applications: a review," Journal of Advanced Scientific Research, vol. 3, no. 2, pp. 25-29, 2012.

[20] P. Yuan, D. Tan, and F. Annabi-Bergaya, "Properties and applications of halloysite nanotubes: recent research advances and future prospects," Applied Clay Science, vol. 112-113, pp. 7593, 2015.

[21] G. J. Churchman, T. J. Davy, L. A. G. Aylmore, R. J. Gilkes, and P. G. Self, "Characteristics of fine pores in some halloysites," Clay Minerals, vol. 30, no. 2, pp. 89-98, 1995.

[22] E. Joussein, S. Petit, J. Churchman, B. Theng, D. Righi, and B. Delvaux, "Halloysite clay minerals-a review," Clay Minerals, vol. 40, no. 4, pp. 383-426, 2005.

[23] T. V. Brantseva, S. O. Ilyin, I. Y. Gorbunova, S. V. Antonov, Y. M. Korolev, and M. L. Kerber, "Epoxy reinforcement with silicate particles: rheological and adhesive properties-part II: characterization of composites with halloysite," International Journal of Adhesion and Adhesives, vol. 68, pp. 248-255, 2016.

[24] R. Atif and F. Inam, "Influence of macro-topography on damage tolerance and fracture toughness of $0.1 \mathrm{wt} \%$ multi-layer graphene/clay-epoxy nanocomposites," Polymers, vol. 8, no. 7, p. 239, 2016.

[25] R. Atif and F. Inam, "Influence of macro-topography on damage tolerance and fracture toughness of $0.1 \mathrm{wt} \%$ multi-layer graphene/clay-epoxy nanocomposites," Polymers, vol. 8, no. 7, article 239, 2016.
[26] R. Atif and F. Inam, "Fractography analysis of $0.5 \mathrm{wt} \%$ multi layer graphene/nanoclay reinforced nanocomposites," AIMS Materials Science, vol. 3, no. 4, pp. 1294-1308, 2016.

[27] M. Du, B. Guo, and D. Jia, "Thermal stability and flame retardant effects of halloysite nanotubes on poly(propylene)," European Polymer Journal, vol. 42, no. 6, pp. 1362-1369, 2006.

[28] S. Deng, J. Zhang, L. Ye, and J. Wu, "Toughening epoxies with halloysite nanotubes," Polymer, vol. 49, no. 23, pp. 5119-5127, 2008.

[29] M. T. Albdiry and B. F. Yousif, "Morphological structures and tribological performance of unsaturated polyester based untreated/silane-treated halloysite nanotubes," Materials and Design, vol. 48, pp. 68-76, 2013.

[30] Y. Tang, S. Deng, L. Ye et al., "Effects of unfolded and intercalated halloysites on mechanical properties of halloysiteepoxy nanocomposites," Composites Part A: Applied Science and Manufacturing, vol. 42, no. 4, pp. 345-354, 2011.

[31] M. Quaresimin, M. Salviato, and M. Zappalorto, "Fracture and interlaminar properties of clay-modified epoxies and their glass reinforced laminates," Engineering Fracture Mechanics, vol. 81, pp. 80-93, 2012.

[32] M. Zappalorto, M. Salviato, and M. Quaresimin, "Mixed mode (I+II) fracture toughness of polymer nanoclay nanocomposites," Engineering Fracture Mechanics, vol. 111, pp. 50-64, 2013.

[33] V. Vahedi and P. Pasbakhsh, "Instrumented impact properties and fracture behaviour of epoxy/modified halloysite nanocomposites," Polymer Testing, vol. 39, pp. 101-114, 2014.

[34] S. Bhuvana and M. Prabakaran, "Synthesis and characterisation of polyamide/halloysite nanocomposites prepared by solution intercalation method," Nanoscience and Nanotechnology, vol. 4, no. 3, pp. 44-51, 2014.

[35] M. H. Gabr, N. T. Phong, M. A. Abdelkareem et al., "Mechanical, thermal, and moisture absorption properties of nano-clay reinforced nano-cellulose biocomposites," Cellulose, vol. 20, no. 2, pp. 819-826, 2013.

[36] S. Horsch, G. Serhatkulu, E. Gulari, and R. M. Kannan, "Supercritical $\mathrm{CO}_{2}$ dispersion of nano-clays and clay/polymer nanocomposites," Polymer, vol. 47, no. 21, pp. 7485-7496, 2006.

[37] E. Sancaktar and J. Kuznicki, "Nanocomposite adhesives: mechanical behavior with nanoclay," International Journal of Adhesion and Adhesives, vol. 31, no. 5, pp. 286-300, 2011.

[38] J. Asadi, N. G. Ebrahimi, and M. Razzaghi-Kashani, "Selfhealing property of epoxy/nanoclay nanocomposite using poly(ethylene-co-methacrylic acid) agent," Composites Part A: Applied Science and Manufacturing, vol. 68, pp. 56-61, 2015.

[39] N. N. Bonnia, S. H. Ahmad, I. Zainol, A. A. Mamun, M. D. H. Beg, and A. K. Bledzki, "Mechanical properties and environmental stress cracking resistance of rubber toughened polyester/kenaf composite," eXPRESS Polymer Letters, vol. 4, no. 2, pp. 55-61, 2010.

[40] A. V. Ratna Prasad and K. Mohana Rao, "Mechanical properties of natural fibre reinforced polyester composites: jowar, sisal and bamboo," Materials \& Design, vol. 32, no. 8-9, pp. 4658-4663, 2011.

[41] H. N. Dhakal, Z. Y. Zhang, and M. O. W. Richardson, "Effect of water absorption on the mechanical properties of hemp fibre reinforced unsaturated polyester composites," Composites Science and Technology, vol. 67, no. 7-8, pp. 1674-1683, 2007.

[42] R. Ollier, E. Rodriguez, and V. Alvarez, "Unsaturated polyester/ bentonite nanocomposites: influence of clay modification on final performance," Composites Part A: Applied Science and Manufacturing, vol. 48, no. 1, pp. 137-143, 2013. 
[43] W. Liu, S. V. Hoa, and M. Pugh, "Fracture toughness and water uptake of high-performance epoxy/nanoclay nanocomposites," Composites Science and Technology, vol. 65, no. 15-16, pp. 23642373, 2005.

[44] R. Maharsia, N. Gupta, and H. D. Jerro, "Investigation of flexural strength properties of rubber and nanoclay reinforced hybrid syntactic foams," Materials Science and Engineering A, vol. 417, no. 1-2, pp. 249-258, 2006.

[45] P. Jawahar, R. Gnanamoorthy, and M. Balasubramanian, “Tribological behaviour of clay-thermoset polyester nanocomposites," Wear, vol. 261, no. 7-8, pp. 835-840, 2006.

[46] X. Liu, Q. Wu, L. A. Berglund, J. Fan, and Z. Qi, "Polyamide 6clay nanocomposites/polypropylene-grafted-maleic anhydride alloys," Polymer, vol. 42, no. 19, pp. 8235-8239, 2001.

[47] G. Huang and H. Sun, "Effect of water absorption on the mechanical properties of glass/polyester composites," Materials and Design, vol. 28, no. 5, pp. 1647-1650, 2007.

[48] M. T. Albdiry, H. Ku, and B. F. Yousif, "Impact fracture behaviour of silane-treated halloysite nanotubes-reinforced unsaturated polyester," Engineering Failure Analysis, vol. 35, pp. 718-725, 2013.

[49] Y. Lin, K. M. Ng, C.-M. Chan, G. Sun, and J. Wu, "High-impact polystyrene/halloysite nanocomposites prepared by emulsion polymerization using sodium dodecyl sulfate as surfactant," Journal of Colloid and Interface Science, vol. 358, no. 2, pp. 423$429,2011$. 

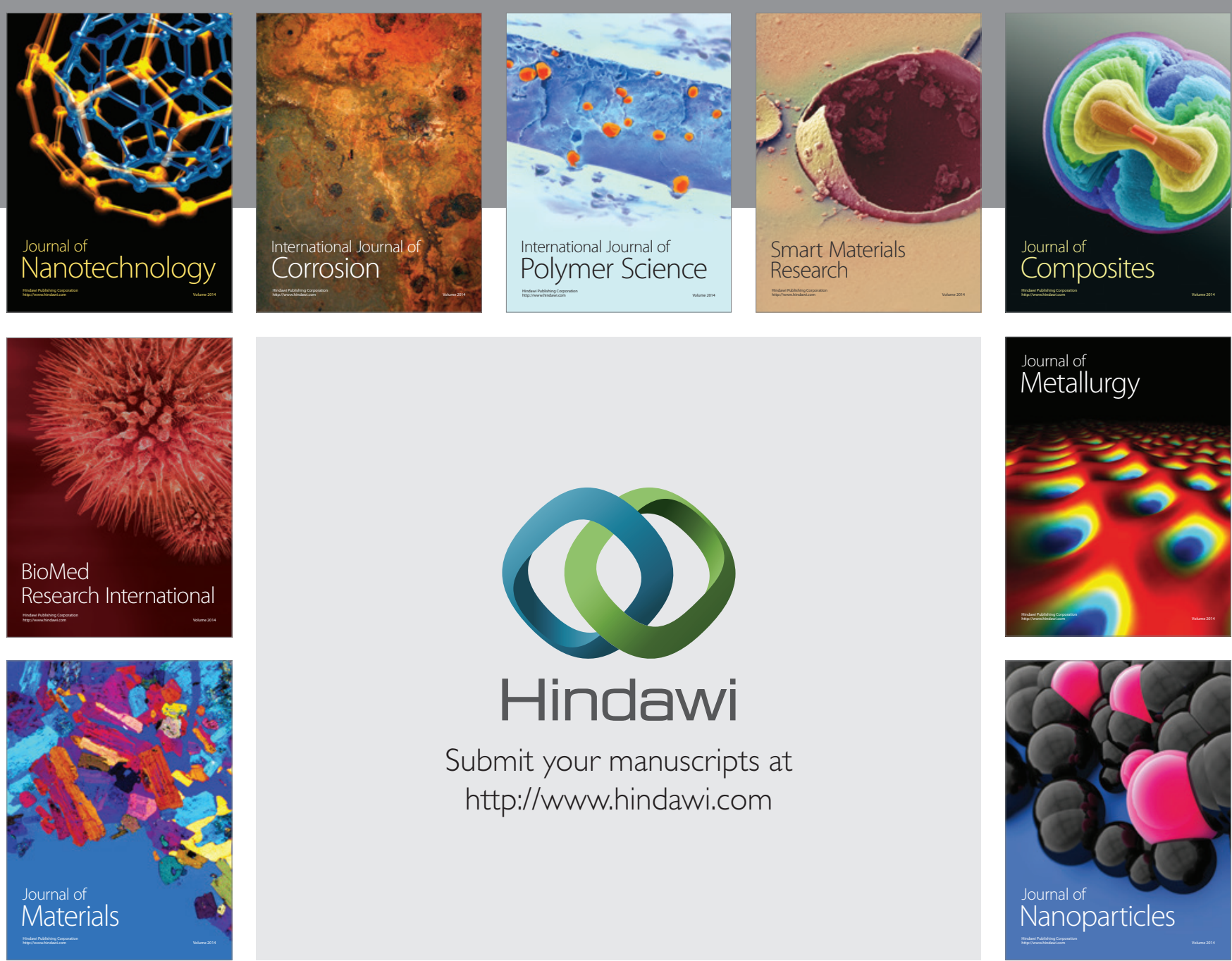

\section{Hindawi}

Submit your manuscripts at

http://www.hindawi.com

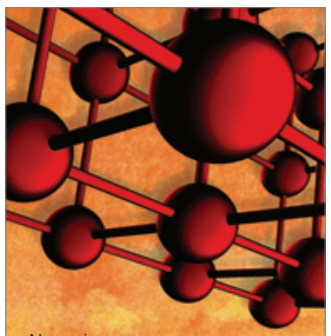

Materials Science and Engineering
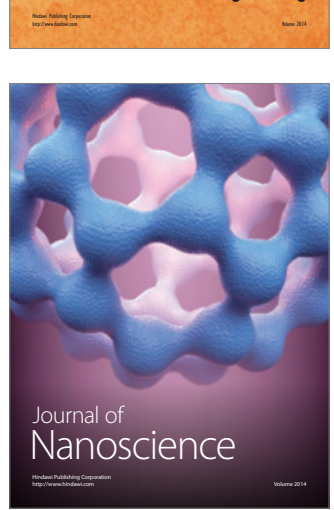
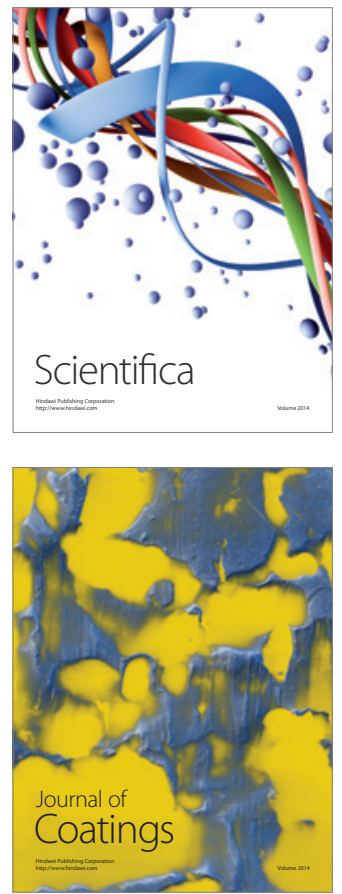
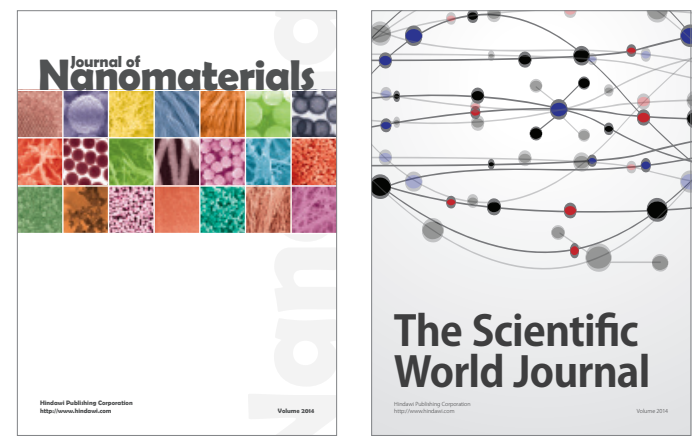

The Scientific World Journal
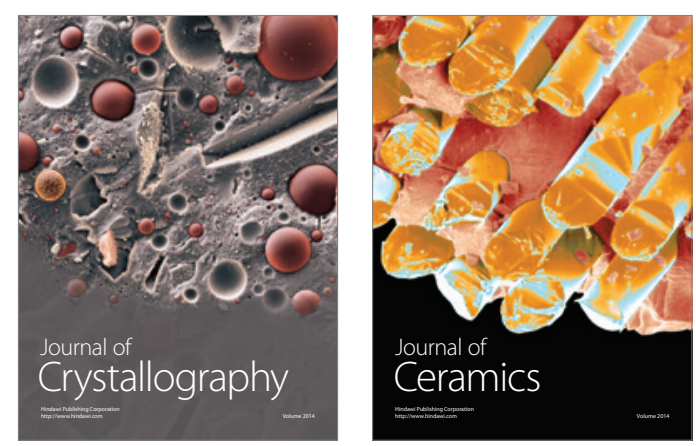
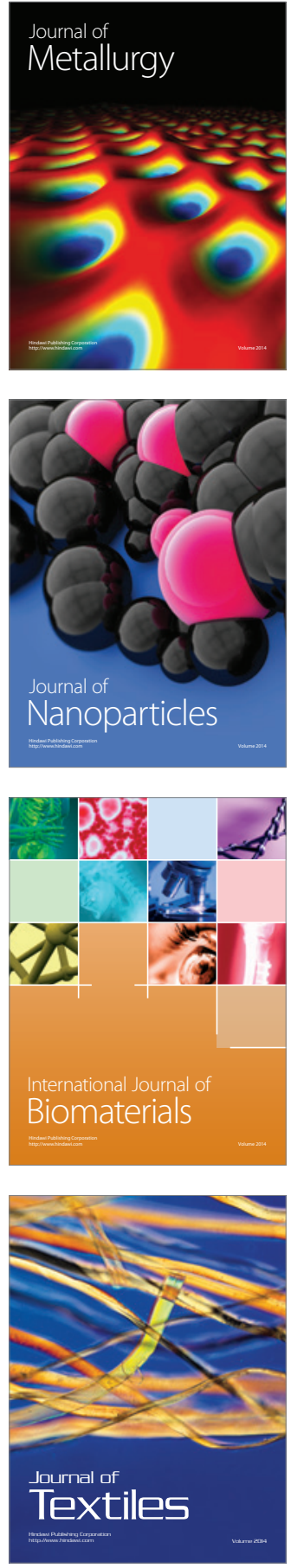